\title{
Quality of Life and Emotional Strain in Caregivers of Patients with Multiple Sclerosis
}

\author{
Petros Petrikis $^{a}$ \\ Anastasia Baldouma ${ }^{\mathrm{b}}$ \\ Aristeidis H. Katsanos ${ }^{b, c}$ \\ Spyridon Konitsiotis ${ }^{b}$ \\ Sotirios Giannopoulos ${ }^{\mathrm{b}, \mathrm{c}}$ \\ ${ }^{\text {aP }}$ sychiatric Clinic, \\ ${ }^{b}$ Department of Neurology, and \\ ${ }^{\circ}$ Neurosurgical Research Institute, \\ School of Medicine, \\ University of Ioannina, Ioannina, Greece
}

\begin{abstract}
Background and Purpose This study aimed was to measure the quality of life, fatigue, stress, and depression in a consecutive sample of caregivers of multiple sclerosis (MS) patients.

Methods We included data from 131 consecutive caregivers of MS patients [age $=51.2 \pm 12.8$ years $($ mean $\pm S D)$, males $=53.4 \%$, duration of caregiving $=10.0 \pm 6.3$ years]. We assessed the quality of life, fatigue, stress, and depression of the caregivers using the 36-item Short Form Health Survey, Krupp Fatigue Severity Scale, Kingston Caregiver Stress Scale, and Hamilton Scale for Depression, respectively. The disability status of the patients was assessed using the Kurtzke Expanded Disability Status Scale. We used linear regression models to identify possible correlations between all of the aforementioned scales, while multivariable logistic regression models were employed to assess the correlations of caregiver fatigue with caregiver characteristics and patient disability.
\end{abstract}

Results The linear regression analyses revealed that caregiver fatigue was positively associated with stress and negatively correlated with both physical health status and mental health status. Caregiver stress was positively associated with depression and negatively correlated with both physical health status and mental health status. Depression was negatively correlated with both caregiver physical health status and mental health status. In multivariable logistic regression analysis, caregiver fatigue was found to be independently associated with education status [odds ratio $(\mathrm{OR})=0.61,95 \% \mathrm{CI}=0.37$ to 0.99 ], history of chronic disease ( $\mathrm{OR}=5.52,95 \%$ $\mathrm{CI}=1.48$ to 20.55$)$, other chronic diseases in the family $(\mathrm{OR}=7.48,95 \% \mathrm{CI}=1.49$ to 37.47$)$, and the disability status of the patient $(\mathrm{OR}=1.36,95 \% \mathrm{CI}=1.03$ to 1.80$)$.

Conclusions Fatigue, stress, and depression in caregivers of MS patients are negatively correlated with their physical health status and mental health status. Caregiver fatigue is independently associated with education status, history of chronic disease, other chronic disease in the family, and patient disability.

Key Words multiple sclerosis, caregivers, health status, fatigue, depression, quality of life, anxiety.
Received May 28, 2018

Revised August 25, 2018

Accepted August 28, 2018

\section{Correspondence}

Petros Petrikis, MD, $\mathrm{PhD}$

Psychiatric Clinic, School of Medicine, University of Ioannina,

P.O. Box 1186, 45110 Ioannina, Greece

Tel +302651099844

Fax +302651099667

E-mail ppetrikis@hotmail.gr

\section{INTRODUCTION}

Multiple sclerosis (MS) is a chronic, demyelinating disease of the CNS that affects approximately 2.5 million people worldwide and is the most-common cause of neurological disability in young adults. ${ }^{1}$ MS is characterized by episodes of neurological symptoms that are usually followed by neurological deficits that lead to increasing disability over 30-40 years. ${ }^{2,3}$ The disabilities caused by the disorder include fatigue, decreased mobility, bladder and bowel dysfunction, depression, and cognitive impairment. ${ }^{4}$ These disabilities interfere with family life, work, and recreational activities, and require the patients and their families to adjust to lifestyle changes and restrictions. ${ }^{1}$ Half of MS patients will not be able to walk without unaided within 15 years after the onset of illness, and will be unemployed (a) This is an Open Access article distributed under the terms of the Creative Commons Attribution Non-Commercial License (https://creativecommons.org/licenses/by-nc/4.0) which permits unrestricted non-commercial use, distribution, and reproduction in any medium, provided the original work is properly cited. 
within 10 years. ${ }^{4}$ About $30 \%$ of MS patients need home assistance, and in about $80 \%$ of the cases this assistance is provided by informal caregivers, usually family members who mostly comprise their spouses or partners. ${ }^{5-7}$

The assistance provided by informal caregivers covers a wide range of services, such as personal care, homemaking, mobility, and recreational activities. ${ }^{7}$ Caregivers play an important role in supporting patients suffering from MS at home. ${ }^{4}$ Caregivers also have to cope with the unpredictable course and prognosis of MS, including the possibility of the patient becoming severely disabled. ${ }^{8}$ Especially as the disease progresses, caregiving may become physically and emotionally more demanding and time-consuming, a combination that often leads caregivers to neglect their own needs and care, ${ }^{9,10}$ and also even neglect and mistreat patients. ${ }^{11}$ Some caregivers develop feelings of insufficiency and self-blame despite their commitment to the patient and adapting their lifestyle to the needs of the patient. ${ }^{12}$ Distressed caregivers might lose the ability to organize themselves and perform crucial tasks effectively. ${ }^{13}$ As Benito-León et al. ${ }^{14}$ suggested, the emphasis in MS treatment needs to shift from a patient-oriented approach to an approach that combines patients and caregivers, because caregivers are both "hidden patients" and "cotherapists"15 whose well-being is of the utmost importance for the well-being of the patients.

The aim of the present study was to measure the quality of life, fatigue, stress, and depression in caregivers of patients with MS, and to identify further possible correlations among these characteristics and characteristics of caregivers (age, gender, affinity with the patient, duration of caregiving, income, education, and hobbies) and the severity of the patient disability.

\section{METHODS}

\section{Setting, study design, and subjects}

One hundred and thirty-one caregivers of patients suffering from MS [age $=51.2 \pm 12.8$ years $($ mean $\pm S D)$, males $=53.4 \%$, and duration of caregiving $=10.0 \pm 6.3$ years] and the corresponding patients themselves were prospectively enrolled in this study. Their baseline characteristics are presented in Table 1. The MS patients were recruited from the Department of Neurology, University Hospital of Ioannina, Greece from October 2015 to March 2017. The inclusion criteria for the patients were 1) having a definite diagnosis of MS, 2) being stable at the time of the study [defined as no change in the Kurtzke Expanded Disability Status Scale (EDSS) in the 3 months prior to study enrollment], 3) needing a caregiver to help them in everyday life, and 4) able to understand the aim of the study and give informed consent. The exclusion criteria for the patients were 1) acute phase or relapse of MS, 2)
Table 1. Baseline characteristics of the caregivers

\begin{tabular}{|c|c|}
\hline Baseline characteristic & Value $(n=131)$ \\
\hline Age, years & $51.2 \pm 12.8$ \\
\hline Males & 53.4 \\
\hline \multicolumn{2}{|l|}{ Length of education (years, \%) } \\
\hline$<7$ & 25.9 \\
\hline $7-9$ & 13.7 \\
\hline $9-12$ & 29.0 \\
\hline$>12$ & 67.6 \\
\hline \multicolumn{2}{|l|}{ Income $(€, \%)$} \\
\hline $0-500$ & 20.6 \\
\hline $501-1,000$ & 22.9 \\
\hline $1,001-1,500$ & 33.6 \\
\hline $1,501-2,000$ & 9.2 \\
\hline $2,001-3,000$ & 9.2 \\
\hline$>3,000$ & 4.5 \\
\hline \multicolumn{2}{|l|}{ Profession (\%) } \\
\hline Household & 12.3 \\
\hline Retired & 29.0 \\
\hline State employee & 14.5 \\
\hline Private employee & 9.1 \\
\hline Freelance & 16.0 \\
\hline Unemployed & 6.8 \\
\hline Farmer & 12.3 \\
\hline \multicolumn{2}{|l|}{ Affinity (\%) } \\
\hline Parent & 29.8 \\
\hline Spouse & 55.7 \\
\hline Child & 3.1 \\
\hline Sibling & 8.4 \\
\hline Other relatives & 1.5 \\
\hline Friend & 2.2 \\
\hline History of personal disease (\%) & 12.2 \\
\hline History of other diseases in the family (\%) & 9.9 \\
\hline Duration of caregiving, years & $10.0 \pm 6.3$ \\
\hline Main caregiver $(\%)$ & 89.3 \\
\hline \multicolumn{2}{|l|}{ Number of other caregivers (\%) } \\
\hline 0 & 77.1 \\
\hline 1 & 16.0 \\
\hline 2 & 6.9 \\
\hline Psychotherapy (\%) & 7.6 \\
\hline Sports/hobbies (\%) & 38.2 \\
\hline KCSS score & $24.9 \pm 9.6$ \\
\hline Family & $3.5 \pm 2.2$ \\
\hline Financial status & $2.7 \pm 1.6$ \\
\hline FSS score & $3.4 \pm 1.8$ \\
\hline SF-36 score (PCS) & $50.8 \pm 9.2$ \\
\hline SF-36 score (MCS) & $42.8 \pm 12.2$ \\
\hline HAM-D score & $8.0 \pm 6.3$ \\
\hline Very severe depression (HAM-D score $\geq 23, \%$ ) & 12.2 \\
\hline EDSS score & $3.8 \pm 2.1$ \\
\hline
\end{tabular}

Data are mean $\pm S D$, percentage values.

EDSS: Expanded Disability Status Scale, FSS: Fatigue Severity Scale, HAM-D: Hamilton Scale for Depression, KCSS: Kingston Caregiver Stress Scale, MCS: mental component summary, PCS: physical component summary, SF-36: 36-item Short Form Health Survey. 
change in the EDSS score during the previous 3 months, 3) coexistence with another disabling disease not related to MS, 4) diagnosis of dementia according to Diagnostic and Statistical Manual of Mental Disorders-5 criteria, 5) history of alcohol or substance abuse, or 6) refusing to give informed consent.

For the caregivers, defined as the persons who provided informal care on a regular basis, the inclusion criteria were 1) living with the patient and being responsible for his/her everyday care and well-being, and 2) not being paid for caregiving.

The complete study protocol was approved prior to study initiation by the ethics committee of the University Hospital of Ioannina (IRB approval number: 875-21.12.2015). Written informed consent was obtained from all patients and caregivers prior to study enrollment.

\section{Methods}

\section{Caregiver assessments}

The quality of life of the caregivers was assessed using the 36-item Short Form Health Survey (SF-36) (non-commercial license agreement, Office of Grants and Scholarly Research, OPTUM; License number: OM 029174).

The SF-36 measures physical and mental health in the following eight dimensions: vitality, physical functioning, body pain, general health perceptions, physical role functioning, emotional role functioning, social role functioning, and mental health. These eight dimensions are scaled so that the total score of the SF-36 ranges from 0 to 100, with lower scores meaning greater disability. ${ }^{16}$ The SF-36 is one of the most widely used quality-of-life instruments, and it exhibits high validity and reliability. ${ }^{17}$

Fatigue was assessed using the Krupp Fatigue Severity Scale (FSS) that includes nine items related to fatigue and its impact on everyday activities. Each item is scored from 1 to 7 , and a total score of 36 or more indicates the presence of fatigue. The FSS was chosen because it possesses high sensitivity, reliability, and internal consistency in assessments of fatigue. ${ }^{18}$

Stress was assessed with the Kingston Caregiver Stress Scale (KCSS), which consists of ten questions dealing with caregiving, family, and financial status (seven, two, and one question, respectively). Each answer is scored from 1 (no stress) to 5 (extreme stress). ${ }^{19} \mathrm{KCSS}$ is especially suitable for assessing unpaid caregivers, usually the partner or other relatives of the patient, and has satisfactory psychometric properties. ${ }^{20}$

Caregiver depression was assessed using the Hamilton Scale for Depression (HAM-D). This scale consists of 21 items, with the score being based on the first 17:8 are scored on a 5-point scale ranging from 0 (not present) to 4 (severe), and 9 are scored from 0 to $2 .{ }^{21}$ For evaluating the HAM-D scores, we adopted the severity ranges for the HAM-D reported by Zimmermann et al..$^{22}$ as follows: no depression (score of 0-7), mild depression (8-16), moderate depression (17-22), and severe depression $(\geq 23)$. The HAM-D has been considered a gold standard for assessing the severity of depression in both clinical settings and research. ${ }^{23}$

We used validated Greek versions of the SF- $36,{ }^{24} \mathrm{FSS},{ }^{25}$ KCSS ${ }^{20}$ and HAM-D. ${ }^{26}$

\section{Patient assessments}

The EDSS was applied by an experienced neurologist to rate the disability status of each patient. ${ }^{27}$

\section{Statistical analysis}

We first used linear regression models to identify correlations of the KCSS and its three domains (caregiving, family, and financial status) with both the HAM-D and the two domains of the SF-36 [physical component summary (PCS) and mental component summary (MCS)]. Additional linear regression analyses were performed to investigate the association of both the PCS and MCS of the SF-36 with the FSS and HAM-D. We then used univariable and multivariable logistic regression analyses to investigate possible associations of all baseline ordinal characteristics of the caregivers and the severity of patient disability (quantified by the EDSS score) with the caregiver fatigue status, as expressed by the numerical values on the corresponding scale. All baseline characteristics that contributed to the outcome of interest in the initial univariable analyses at $p$ values $<0.1$ were included in the multivariable model as candidate variables. The final variables that were independently associated in the multivariable logistic regression analyses with the outcome of interest were selected by a backward stepwise selection procedure using a $p$ value of $<0.05$. Finally, the association of caregiver fatigue with baseline non-ordinal characteristics regarding the caregiver profession and their affinity with the patient was assessed using a one-way ANOVA.

All statistical analyses were performed using the stata statistical software (release 13 for Windows, StataCorp., College Station, TX, USA).

\section{RESULTS}

Caregivers had scores on the FSS, KCSS, and HAM-D of 3.4 \pm $1.8,24.9 \pm 9.6$, and $8.0 \pm 6.3$, respectively, with severe depression (HAM-D score $\geq 23$ ) reported in $12.2 \%$. Their SF-36 scores for the PCS and MCS were $50.8 \pm 9.2$ and $42.8 \pm 12.2$, respectively.

In linear regression analyses (Table 2 and 3), caregiver fatigue was found to be positively associated with stress, as as- 
Emotional Strain in MS Caregivers

Table 2. Associations of the KCSS with the FSS, HAM-D, and SF-36

\begin{tabular}{lcccccccc}
\hline & FSS score & $\boldsymbol{p}$ & HAM-D score & $\boldsymbol{p}$ & PCS & $\boldsymbol{p}$ & MCS & $\boldsymbol{p}$ \\
\hline KCSS score & $0.38(0.30$ to 0.46$)$ & $<0.001$ & $0.99(0.79$ to 1.19$)$ & $<0.001$ & $-0.51(-0.67$ to -0.35$)$ & $<0.001$ & $-0.49(-0.59$ to -0.38$)$ & $<0.001$ \\
Caregiving & $0.30(0.24$ to 0.36$)$ & $<0.001$ & $0.76(0.59$ to 0.92$)$ & $<0.001$ & $-0.37(-0.50$ to -0.24$)$ & $<0.001$ & $-0.38(-0.46$ to -0.29$)$ & $<0.001$ \\
Family & $0.04(0.02$ to 0.06$)$ & 0.001 & $0.14(0.08$ to 0.19$)$ & $<0.001$ & $-0.07(-0.11$ to -0.03$)$ & 0.001 & $-0.06(-0.09$ to -0.03$)$ & $<0.001$ \\
Financial status & $0.04(0.02$ to 0.05$)$ & $<0.001$ & $0.10(0.06$ to 0.14$)$ & $<0.001$ & $-0.07(-0.09$ to -0.04$)$ & $<0.001$ & $-0.05(-0.07$ to -0.02$)$ & $<0.001$ \\
\hline
\end{tabular}

Data are $r(95 \% \mathrm{Cl})$ values.

FSS: Fatigue Severity Scale, HAM-D: Hamilton Scale for Depression, KCSS: Kingston Caregiver Stress Scale, MCS: mental component summary, PCS: physical component summary, SF-36: 36-item Short Form Health Survey.

Table 3. Associations of the FSS and HAM-D with the SF-36

\begin{tabular}{lcccc}
\hline & PCS & $\boldsymbol{p}$ & MCS & $\boldsymbol{p}$ \\
\hline FSS score & $-1.11(-1.35$ to -0.88$)$ & $<0.001$ & $-0.75(-0.94$ to -0.56$)$ & $<0.001$ \\
HAM-D score & $-0.30(-0.41$ to -0.19$)$ & $<0.001$ & $-0.33(-0.40$ to -0.26$)$ & $<0.001$ \\
\hline
\end{tabular}

Data are $r(95 \% \mathrm{Cl})$ values.

FSS: Fatigue Severity Scale, HAM-D: Hamilton Scale for Depression, MCS: mental component summary, PCS: physical component summary, SF-36: 36-item Short Form Health Survey.

sessed using the KCSS ( $r=0.38,95 \% \mathrm{CI}=0.30$ to $0.46, p<$ 0.001 ), and negatively correlated with both physical health status $(r=-1.11,95 \% \mathrm{CI}=-1.35$ to $-0.88, p<0.001)$ and mental health status $(r=-0.75,95 \% \mathrm{CI}=-0.94$ to $-0.56, p<0.001)$. Similarly, caregiver stress (as assessed using the KCSS) was found to be positively associated with depression $(r=0.99,95 \% \mathrm{CI}=$ 0.79 to $1.19, p<0.001$ ) and negatively correlated with both the physical health status ( $r=-0.51,95 \% \mathrm{CI}=-0.67$ to $-0.35, p<$ 0.001 ) (Fig. $1 \mathrm{~A}$ ) and mental health status ( $\mathrm{r}=-0.49,95 \% \mathrm{CI}=$ -0.59 to $-0.38, p<0.001$; Fig. $1 \mathrm{~B}$ ). Finally, depression (as assessed with the HAM-D) was negatively correlated with both the PCS $(r=-0.30,95 \%$ CI $=-0.41$ to $-0.19, p<0.001)$ and MCS $(r=-0.33,95 \%$ CI $=-0.40$ to $-0.26, p<0.001)$ of the SF-36.

In the univariable analysis of the associations of nonordinal baseline characteristics (Table 4), caregiver profession was significantly associated with fatigue ( $p=0.038$ ), with unemployed caregivers reporting fatigue symptoms more often than the other categories. Similarly, the reported fatigue level varied significantly according to the affinity of the caregiver with the patient $(p=0.027)$. In the univariable logistic regression analysis (Table 5), caregiver age ( $p=0.001)$, education ( $p=$ $0.002)$, sports $(p=0.006)$, history of chronic disease $(p=0.002)$, other chronic disease in the family $(p=0.012)$, and the disability status of the patient $(p=0.023)$ were significantly associated with caregiver fatigue. In multivariable logistic regression analyses (Table 5), caregiver fatigue was independently associated with education status $(\mathrm{OR}=0.61,95 \% \mathrm{CI}=0.37$ to $0.99, p=$ $0.046)$, history of chronic disease $(\mathrm{OR}=5.52,95 \% \mathrm{CI}=1.48$ to $20.55, p=0.011$ ), other chronic disease in the family ( $\mathrm{OR}=7.48$, $95 \% \mathrm{CI}=1.49$ to $37.47, p=0.014)$ and disability status of the patient $(\mathrm{OR}=1.36,95 \% \mathrm{CI}=1.03$ to $1.80, p=0.032)$.
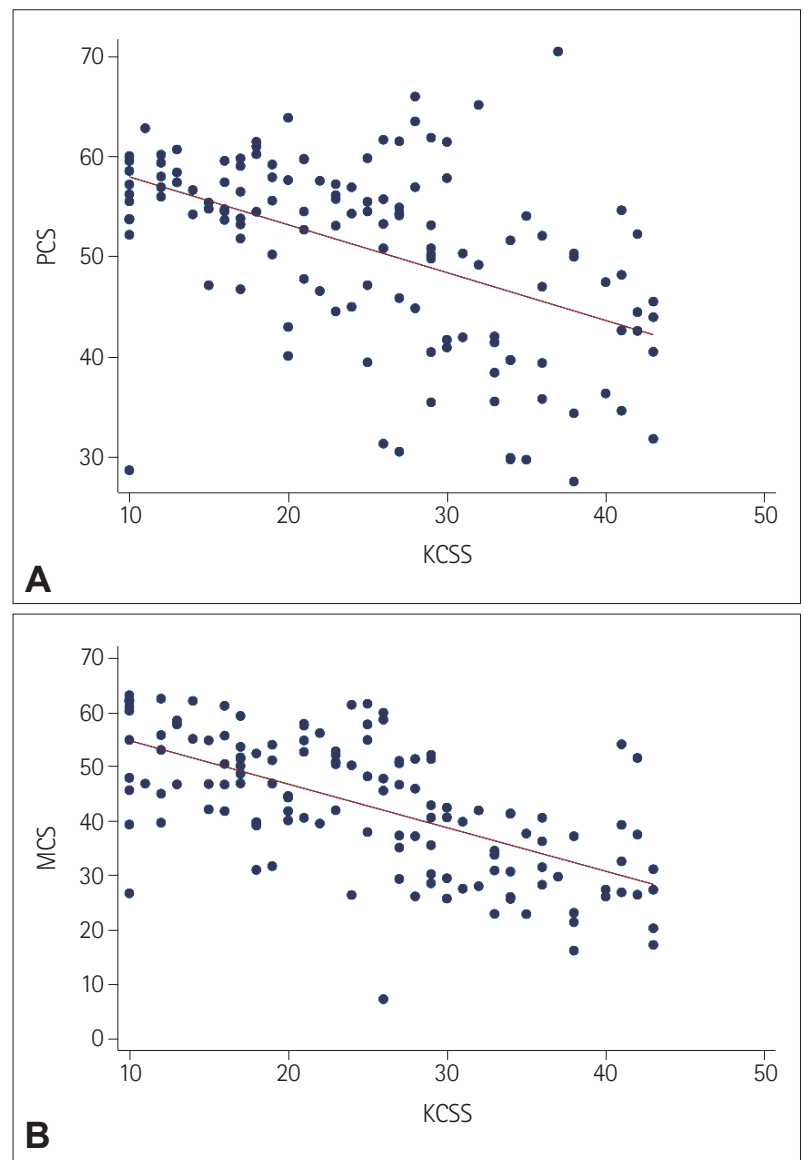

Fig. 1. Association of stress with the physical health status $(A)$ and mental health status (B) of caregivers of patients with multiple sclerosis. Stress was assessed using the KCSS, while physical health status and mental health status were assessed with the PCS and MCS, respectively, of the 36-item Short Form Health Survey. KCSS: Kingston Caregiver Stress Scale, MCS: mental component summary, PCS: physical component summary. 
Table 4. Results from the univariable analysis of the association of baseline nonordinal characteristics with fatigue

\begin{tabular}{|c|c|c|c|c|c|c|c|c|}
\hline Profession & $\begin{array}{l}\text { Household } \\
\qquad(n=16)\end{array}$ & $\begin{array}{l}\text { Retired } \\
(n=38)\end{array}$ & $\begin{array}{l}\text { State employee } \\
\qquad(n=19)\end{array}$ & $\begin{array}{l}\text { Private employee } \\
\qquad(n=12)\end{array}$ & $\begin{array}{c}\text { Freelance } \\
(n=21)\end{array}$ & $\begin{array}{l}\text { Farmer } \\
(n=9)\end{array}$ & $\begin{array}{l}\text { Unemployed } \\
\qquad(n=16)\end{array}$ & $p$ \\
\hline FSS score & $3.65 \pm 1.80$ & $3.84 \pm 1.86$ & $3.01 \pm 1.86$ & $2.60 \pm 1.32$ & $2.75 \pm 1.28$ & $2.45 \pm 1.42$ & $4.15 \pm 2.09$ & 0.038 \\
\hline Affinity & $\begin{array}{l}\text { Parent } \\
(n=39)\end{array}$ & $\begin{array}{l}\text { Spouse } \\
(n=73)\end{array}$ & $\begin{array}{l}\text { Child } \\
(n=4)\end{array}$ & $\begin{array}{l}\text { Sibling } \\
(n=11)\end{array}$ & $\begin{array}{l}\text { Other relative } \\
\qquad(n=2)\end{array}$ & $\begin{array}{l}\text { Professional caregiver } \\
\qquad(n=1)\end{array}$ & $\begin{array}{l}\text { Friend } \\
(n=1)\end{array}$ & $p$ \\
\hline FSS score & $4.34 \pm 1.88$ & $3.05 \pm 1.63$ & $2.05 \pm 1.34$ & $3.0 \pm 1.44$ & $1.83 \pm 0.55$ & 3.78 & 2.33 & 0.027 \\
\hline
\end{tabular}

FSS: Fatigue Severity Scale.

Table 5. Results from the univariable and multivariable logistic regression analyses ofthe association of baseline ordinal characteristics with fatigue

\begin{tabular}{|c|c|c|c|c|}
\hline \multirow{2}{*}{ Variable } & \multicolumn{2}{|c|}{ Univariable logistic regression analysis } & \multicolumn{2}{|c|}{ Multivariable logistic regression analysis } \\
\hline & OR $(95 \% \mathrm{Cl})$ & $p$ & OR $(95 \% \mathrm{Cl})$ & $p$ \\
\hline Age & 1.07 (1.03 to 1.11$)$ & 0.001 & 1.00 (0.96 to 1.06$)$ & 0.600 \\
\hline Gender (male) & 0.65 (0.29 to 1.45$)$ & 0.292 & - & - \\
\hline Education & 0.56 (0.39 to 0.81) & 0.002 & 0.61 (0.37 to 0.99) & 0.046 \\
\hline Income & 0.81 (0.59 to 1.11) & 0.184 & - & - \\
\hline Chronic disease of caregiver & $5.43(1.82$ to 16.19$)$ & 0.002 & 5.52 (1.48 to 20.55$)$ & 0.011 \\
\hline Other chronic disease in the family & 4.57 (1.40 to 14.85$)$ & 0.012 & 7.48 (1.49 to 37.47$)$ & 0.014 \\
\hline Duration of care & 0.99 (0.93 to 1.06) & 0.941 & - & - \\
\hline Number of other caregivers & 1.04 (0.84 to 1.28$)$ & 0.717 & - & - \\
\hline Sports & 0.23 (0.08 to 0.66$)$ & 0.006 & 0.33 (0.10 to 1.08$)$ & 0.067 \\
\hline EDSS score & 1.27 (1.03 to 1.56$)$ & 0.023 & 1.36 (1.03 to 1.80$)$ & 0.032 \\
\hline
\end{tabular}

EDSS: Expanded Disability Status Scale, OR: odds ratio.

\section{DISCUSSION}

This study found that caregivers experienced high levels of stress, as indicated by a KCSS score of $24.9 \pm 9.6$, and a reduced quality of life, as indicated by PCS and MCS scores on the SF-36 of $50.8 \pm 9.2$ and $42.8 \pm 12.2$, respectively. We also found high rates of clinical depression in caregivers, with very severe depression (HAM-D score $\geq 23$ ) reported in $12.2 \%$ ( $n=$ $16)$, severe depression in $3.8 \%(n=5)$, and moderate depression in $9.2 \%(n=12)$ of the caregivers. Depression was negatively correlated with both physical health status and mental health status, and positively correlated with fatigue and caregiver stress. Labiano-Fontcuberta et al. ${ }^{28}$ reported depressive symptoms in $25 \%$ of a sample of 63 caregivers of MS patients, with $19 \%$ and $1 \%$ having moderate and severe depression, respectively. The caregivers with more depressive symptoms were mainly females and had greater comorbidity (additional diseases).

Caregiver fatigue was associated with their education status, history of chronic disease, history of other chronic disease in the family, their affinity with the patient, and the disability status of the patient. It was particularly notable that unemployed caregivers reported fatigue symptoms more often than the other categories. Employment seems to contribute to the well-being of caregivers. As other studies have suggested, wellbeing is associated with the ability of individuals to find life goals and a meaning-making system in their lives. The impor- tance individuals give to life domains such as family, work, social relationships, and hobbies is crucial in determining how a domain contributes to their life well-being. Professional life functions as a protective factor against fatigue among caregivers, and age, gender, and personality characteristics may also play roles. ${ }^{29}$ The present study found that caregiver fatigue was not associated with gender or age. Males constituted $53.4 \%$ of our caregiver sample. That is in accordance with other studies, because MS is more prevalent in women and so men are more likely to be the spousal caregivers. According to Lee et al., ${ }^{30}$ women caregivers tend to experience higher levels of strain, higher needs for emotional support, and higher perceived social support. However, no statistically significant difference was observed between the male and female caregivers in our sample.

Caregiver stress was correlated with physical disability of the patients (as measured by the EDSS), which is in accordance with previous reports of this factor being a strong indicator of caregiver stress. ${ }^{8,31}$ Katsavos et al. ${ }^{32}$ reported that caregiver stress was positively correlated with age, EDSS score, and disease duration, and negatively with cognitive, physical, and mental health. Depression in MS patients seems to be strongly correlated with depressive symptoms in caregivers, resulting in a less-satisfying relationship, reducing the motivation and investment of the caregiver in his/her role. ${ }^{8}$ The present study found that the severity of illness and the history of other chronic disease in the family were significantly correlated with care- 
giver strain, although illness duration did not to influence caregiver strain. This could have been due to caregivers tending to get used to the diagnosis of MS but not to its severe consequences. Income does not seem to play a role in caregiver strain, although low income imposes restrictions on leisure activities, while education and employment does. Caregivers with higher education and who are employed experience less strain, perhaps because employment gives them the opportunity to change their roles and obligations as well as to have social relationships unrelated to the MS patient.

Despite the strengths of our study associated with its prospective design and the consecutive enrollment of both patients and caregivers, some limitations should also be acknowledged. First, since our sample was small and representative of an urban population in northwestern Greece, the obtained results might not be applicable to other populations. Second, the patient sample consisted of an ambulatory outpatient MS population and thus the more severely affected patients who require extensive or permanent nursing-home care were underrepresented. Finally, it should be noted that our patient group did not undergo an extensive neuropsychological assessment, and so we cannot draw any conclusions about a possible correlation between cognitive deficits of the patients and caregiver stress.

In conclusion, this study found that caregiver strain was positively correlated with the severity of illness, history of other chronic disease in the caregiver or another family member, their affinity with the patient, and the education of the caregiver. Illness duration, income, and caregiver hobbies do not seem to influence caregiver strain. We also found that high rates of depression in caregivers were positively correlated with caregiver stress and negatively with physical health status and mental health status as expressed in SF-36 scores. Future studies need to further elucidate the great impact that the psychological condition of caregivers has on the quality of life of MS patients.

\section{Conflicts of Interest}

The authors have no financial conflicts of interest.

\section{Acknowledgements}

The authors thank OPTUM for the license to use the SF-36 (License number: OM 029174).

\section{REFERENCES}

1. Khan F, Pallant J, Brand C. Caregiver strain and factors associated with caregiver self-efficacy and quality of life in a community cohort with multiple sclerosis. Disabil Rehabil 2007;29:1241-1250.

2. Phillips CJ. The cost of multiple sclerosis and the cost effectiveness of disease-modifying agents in its treatment. CNS Drugs 2004;18:561574 .

3. Campbell JD, Ghushchyan V, Brett McQueen R, Cahoon-Metzger S, Livingston T, Vollmer T, et al. Burden of multiple sclerosis on direct, indirect costs and quality of life: National US estimates. Mult Scler Relat Disord 2014;3:227-236.

4. McKeown LP, Porter-Armstrong AP, Baxter GD. Caregivers of people with multiple sclerosis: experiences of support. Mult Scler 2004;10: 219-230.

5. Minden SL, Frankel D, Hadden LS, Srinath KP, Perloff JN. Disability in elderly people with multiple sclerosis: an analysis of baseline data from the Sonya Slifka Longitudinal Multiple Sclerosis Study. NeuroRehabilitation 2004;19:55-67.

6. Pozzilli C, Palmisano L, Mainero C, Tomassini V, Marinelli F, Ristori $\mathrm{G}$, et al. Relationship between emotional distress in caregivers and health status in persons with multiple sclerosis. Mult Scler 2004;10: 442-446.

7. Buchanan RJ, RadinD, Huang C, Zhu L. Caregiver perceptions associated with risk of nursing home admission for people with multiple sclerosis. Disabil Health J 2010;3:117-124.

8. Figved N, Myhr KM, Larsen JP, Aarsland D. Caregiver burden in multiple sclerosis: the impact of neuropsychiatric symptoms. J Neurol Neurosurg Psychiatry 2007;78:1097-1102.

9. Penwell-Waines L, Goodworth MC, Casillas RS, Rahn R, Stepleman L. Perceptions of caregiver distress, health behaviors, and provider health-promoting communication and their relationship to stress management in MS caregivers. Health Commun 2016;31:478-484.

10. Buchanan R, Huang C. Health-related quality of life among informal caregivers assisting people with multiple sclerosis. Disabil Rehabil 2011; 33:113-121.

11. Shapiro J, Wiglesworth A, Morrison EH. Views on disclosing mistreatment: a focus group study of differences between people with MS and their caregivers. Mult Scler Relat Disord 2013;2:96-102.

12. Golla H, Mammeas S, Galushko M, Pfaff H, Voltz R. Unmet needs of caregivers of severely affected multiple sclerosis patients: a qualitative study. Palliat Support Care 2015;13:1685-1693.

13. Argyriou AA, Karanasios P, Ifanti AA, Iconomou G, Assimakopoulos K, Makridou A, et al. Quality of life and emotional burden of primary caregivers: a case-control study of multiple sclerosis patients in Greece. Qual Life Res 2011;20:1663-1668.

14. Benito-León J, Rivera-Navarro J, Guerrero AL, de Las Heras V, Balseiro J, Rodríguez E, et al. The CAREQOL-MS was a useful instrument to measure caregiver quality of life in multiple sclerosis. J Clin Epidemiol 2011;64:675-686.

15. Antoine P, Quandalle S, Christophe V. Living with a chronically ill relative: assessment of positive and negative dimensions of the experience of natural caregiver. Ann Méd Psychol 2010;168:273-282.

16. McHorney CA, Ware JE Jr, Lu JF, Sherbourne CD. The MOS 36-item Short-Form Health Survey (SF-36): III. Tests of data quality, scaling assumptions, and reliability across diverse patient groups. Med Care 1994;32:40-66.

17. Patti F, Amato MP, Battaglia MA, Pitaro M, Russo P, Solaro C, et al. Caregiver quality of life in multiple sclerosis: a multicentre Italian study. Mult Scler 2007;13:412-419.

18. Krupp LB, LaRocca NG, Muir-Nash J, Steinberg AD. The fatigue severity scale. Application to patients with multiple sclerosis and systemic lupus erythematosus. Arch Neurol 1989;46:1121-1123.

19. Sadak T, Korpak A, Wright JD, Lee MK, Noel M, Buckwalter K, et al. Psychometric evaluation of Kingston Caregiver Stress Scale. Clin Gerontol 2017;40:268-280.

20. Pitsikali A, Galanakis M, Varvogli L, Darviri C. Kingston Caregiver Stress Scale (KCSS) greek validation on dementia caregiver sample. Psychology 2015;6:1180-1186.

21. Hamilton M. Rating depressive patients. J Clin Psychiatry 1980;41: 21-24.

22. Zimmerman M, Martinez JH, Young D, Chelminski I, Dalrymple K. Severity classification on the Hamilton Depression Rating Scale. J Affect Disord 2013;150:384-388.

23. Cusin C, Yang H, Yeung A, Fava M. Rating scales for depression. In: 
Bael L, Blais MA, editors. Handbook of Clinical Rating Scales and Assessment in Psychiatry and Mental Health. New York: Humana Press, 2009;7-10.

24. Pappa E, Kontodimopoulos N, Niakas D. Validating and norming of the Greek SF-36 Health Survey. Qual Life Res 2005;14:1433-1438.

25. Ferentinos P, Kontaxakis V, Havaki-Kontaxaki B, Dikeos D, Lykouras L. Psychometric evaluation of the fatigue severity scale in patients with major depression. Qual Life Res 2011;20:457-465.

26. Stathopoulou H, Karanikola MN, Panagiotopoulou F, Papathanassoglou ED. Anxiety levels and related symptoms in emergency nursing personnel in Greece. J Emerg Nurs 2011;37:314-320; quiz 427.

27. Kurtzke JF. Rating neurologic impairment in multiple sclerosis: an expanded disability status scale (EDSS). Neurology 1983;33:1444-1452.

28. Labiano-Fontcuberta A, Mitchell AJ, Moreno-García S, Benito-León J. Anxiety and depressive symptoms in caregivers of multiple sclerosis patients: the role of information processing speed impairment. $J$
Neurol Sci 2015;349:220-225.

29. Bassi M, Falautano M, Cilia S, Goretti B, Grobberio M, Pattini M, et al. The coexistence of well- and ill-being in persons with multiple sclerosis, their caregivers and health professionals. J Neurol Sci 2014;337: 67-73.

30. Lee EJ, Pieczynski J, DeDios-Stern S, Simonetti C, Lee GK. Gender differences in caregiver strain, needs for support, social support, and quality of life among spousal caregivers of persons with multiple sclerosis. Work 2015;52:777-787.

31. Hakim EA, Bakheit AM, Bryant TN, Roberts MW, McIntosh-Michaelis SA, Spackman AJ, et al. The social impact of multiple sclerosis-a study of 305 patients and their relatives. Disabil Rehabil 2000;22: 288-293.

32. Katsavos S, Artemiadis AK, Zacharis M, Argyrou P, Theotoka I, Chrysovitsanou C, et al. Predicting caregiving status and caregivers' burden in multiple sclerosis. A short report. Neurol Res 2017;39:13-15. 